Article

\title{
In Situ Observation of Liquid Solder Alloys and Solid Substrate Reactions Using High-Voltage Transmission Electron Microscopy
}

\author{
Xin F. Tan ${ }^{1,2} \mathbb{D}$, Flora Somidin ${ }^{1,2,3}$, Stuart D. McDonald ${ }^{1,2} \mathbb{D}$, Michael J. Bermingham ${ }^{2} \mathbb{D}$, Hiroshi Maeno ${ }^{4}$, \\ Syo Matsumura ${ }^{4,5}$ and Kazuhiro Nogita $1,2, * \mathbb{D}$
}

1 Nihon Superior Centre for the Manufacture of Electronic Materials (NS CMEM), School of Mechanical and Mining Engineering, The University of Queensland, St. Lucia, QLD 4072, Australia; xin.tan@uq.edu.au (X.F.T.); flora@unimap.edu.my (F.S.); s.mcdonald1@uq.edu.au (S.D.M.)

2 Advanced Materials Processing and Manufacturing (AMPAM), School of Mechanical and Mining Engineering, The University of Queensland, St. Lucia, QLD 4072, Australia; m.bermingham@uq.edu.au

3 Centre of Excellence Geopolymer and Green Technology, Faculty of Chemical Engineering Technology, Universiti Malaysia Perlis (UniMAP), Taman Muhibbah, Jejawi, Arau 02600, Perlis, Malaysia

4 The Ultramicroscopy Research Center, Kyushu University, Fukuoka 819-0395, Japan; maeno.hiroshi.551@m.kyushu-u.ac.jp (H.M.); matsumura.syo.819@m.kyushu-u.ac.jp (S.M.)

5 Department of Applied Quantum Physics and Nuclear Engineering, Kyushu University, Fukuoka 819-0395, Japan

* Correspondence: k.nogita@uq.edu.au; Tel.: +61-7-3365-3919

check for updates

Citation: Tan, X.F.; Somidin, F.; McDonald, S.D.; Bermingham, M.J.; Maeno, H.; Matsumura, S.; Nogita, K. In Situ Observation of Liquid Solder Alloys and Solid Substrate Reactions Using High-Voltage Transmission Electron Microscopy. Materials 2022, 15, 510. https://doi.org/10.3390/ ma15020510

Academic Editor: Roberto Biagi

Received: 18 November 2021

Accepted: 8 January 2022

Published: 10 January 2022

Publisher's Note: MDPI stays neutral with regard to jurisdictional claims in published maps and institutional affiliations.

Copyright: (C) 2022 by the authors. Licensee MDPI, Basel, Switzerland. This article is an open access article distributed under the terms and conditions of the Creative Commons Attribution (CC BY) license (https:/ / creativecommons.org/licenses/by/ $4.0 /)$.

\begin{abstract}
The complex reaction between liquid solder alloys and solid substrates has been studied ex-situ in a few studies, utilizing creative setups to "freeze" the reactions at different stages during the reflow soldering process. However, full understanding of the dynamics of the process is difficult due to the lack of direct observation at micro- and nano-meter resolutions. In this study, high voltage transmission electron microscopy (HV-TEM) is employed to observe the morphological changes that occur in $\mathrm{Cu}_{6} \mathrm{Sn}_{5}$ between a Sn-3.0 wt\%Ag- $0.5 \mathrm{wt} \% \mathrm{Cu}$ (SAC305) solder alloy and a Cu substrate in situ at temperatures above the solidus of the alloy. This enables the continuous surveillance of rapid grain boundary movements of $\mathrm{Cu}_{6} \mathrm{Sn}_{5}$ during soldering and increases the fundamental understanding of reaction mechanisms in solder solid/liquid interfaces.
\end{abstract}

Keywords: $\mathrm{Pb}$-free solders; high voltage transmission electron microscopy; $\mathrm{Cu}_{6} \mathrm{Sn}_{5}$

\section{Introduction}

In compliance with the Restriction of Use of Certain Hazardous Substances (RoHS) Directive of the European Community, Pb-free solders have been developed. Today, as the primary $\mathrm{Pb}$-free solder used in the electronics industry, the $\mathrm{Sn}-3.0 \mathrm{wt} \% \mathrm{Ag}-0.5 \mathrm{wt} \% \mathrm{Cu}$ (SAC305) solder has found widespread application in electronic interconnects due to its relatively low solidus and liquidus at $217^{\circ} \mathrm{C}$ and $220^{\circ} \mathrm{C}$, respectively [1]. The soldering process involves heating the solder alloy above its melting temperature to react with the $\mathrm{Cu}$ substrate to form an intimate bond. During this process, $\mathrm{Cu}_{6} \mathrm{Sn}_{5}$ and $\mathrm{Cu}_{3} \mathrm{Sn}$ intermetallic compounds (IMCs) form at the interface between the solder melt and the $\mathrm{Cu}$ substrates $[2,3]$. The reactions at the interfaces between liquid solder $/ \mathrm{Cu}_{6} \mathrm{Sn}_{5} / \mathrm{Cu}_{3} \mathrm{Sn} /$ solid substrates are complex. Since understanding the properties of these IMCs is critical for improving solder joint reliability, much research has been conducted using microscopy techniques at room temperature or below the solidus temperature of the solder [4-6]. Using in situ heating/cooling high voltage transmission electron microscopy (HV-TEM) techniques, the stabilities and phase transformation kinetics of $\mathrm{Cu}_{6} \mathrm{Sn}_{5}$ in solder joints have been studied by Somidin et al. [4-6]. However, the requirement for a solid sample makes TEM observations difficult at high temperatures where the reactions take place. While 
in situ synchrotron X-ray imaging has revealed the reactions between liquid solders and $\mathrm{Cu}$ substrates at micrometer scales $[7,8]$, the nano- and submicron- level observations and understanding of the reactions at the liquid/solid interface remain unresolved. Creative experimental setups, including fast dipping and pulling a $\mathrm{Cu}$ coupon into and from a solder bath [9], quenching the joint in liquid nitrogen [10] and removing the molten solder by centrifugal forces [11], have been used to interrupt the reactions at different stages during the soldering process, providing snapshots of the high temperature microstructures. However, full understanding of the dynamics of the process is difficult due to the lack of continuous direct observation. In situ TEM observation of the solid-liquid interface has been achieved in Al-Si systems, relying on the Al oxide film to contain the liquid despite the high vapor pressures in the Al-Si system [12]. The solid-liquid interfaces of pure Al, In and $\mathrm{Sn}$, along with alumina and a few binary alloys [13], Pb-Sn [14] and Pb-free solders [15] on Ni-P substrates were also studied by the same group under in situ heating TEM. TEM observations of nanometer-sized Sn-Bi [16,17] and pure metal [18] particles in the liquid state have also been achieved. In this study, qualitatively, but for the first time, using HV-TEM, we observed the morphological changes in $\mathrm{Cu}_{6} \mathrm{Sn}_{5}$ that has formed through a reaction of SAC305 and a Cu substrate via in situ observations at elevated temperatures up to a peak of $218{ }^{\circ} \mathrm{C}$, just above the solidus of SAC305.

\section{Materials and Methods}

The TEM experiment was conducted with a HV-TEM (JEM-1300NEF JEOL, Akishima, Japan) at an accelerating voltage of $1250 \mathrm{kV}$. At this voltage, the beam induced heating due to inelastic scattering is less than what occurs in conventional TEMs due to the smaller interaction cross-section [4,6]. A double-tilt heating TEM holder (EM-HSTH JEOL, Akishima, Japan) equipped with a thermocouple in contact with a resistive heating element was used to heat the sample and to tilt the sample to appropriate crystal zone axes. Since the $\mathrm{Cu}_{6} \mathrm{Sn}_{5}$ grains have a size range between $2-5 \mu \mathrm{m}$, thinning the TEM lamellar to $<200 \mathrm{~nm}$ as limited by conventional TEMs operating between $200-300 \mathrm{kV}$ would result in a thin film sample where edge effects may dominate. Melting point depression also becomes increasingly significant below $100 \mathrm{~nm}[18,19]$. Therefore, in this study, high voltage TEM was used to enable a sample thickness of approximately $500 \mathrm{~nm}$ to maintain a thickness: grain size ratio above 1:10.

A $500 \mu \mathrm{m}$ diameter SAC305 solder ball (supplied by Nihon Superior Co. Ltd., Osaka, Japan) was reflow soldered on a $\mathrm{Cu}$ pad with organic solderability preservative surface finish (OSP-Cu) to fabricate a $\mathrm{Cu} / \mathrm{IMCs} / \mathrm{SAC}$ solder joint. The joint was embedded in epoxy resin and polished with standard metallographic procedures for scanning electron microscopy (SEM) of the cross-section. SEM and energy dispersive X-ray spectroscopy (EDS) elemental mapping were performed on a Hitachi TM3030 tabletop SEM at an accelerating voltage of $15 \mathrm{kV}$. Images were taken in backscattered electron mode (BSE).

A second $\mathrm{Cu} / \mathrm{IMC} / \mathrm{SAC}$ joint was subsequently annealed at $150{ }^{\circ} \mathrm{C}$ for $500 \mathrm{~h}$ to ensure a full transformation from the high temperature $\eta-\mathrm{Cu}_{6} \mathrm{Sn}_{5}$ crystal structure to the room temperature $\eta^{\prime}-\mathrm{Cu}_{6} \mathrm{Sn}_{5}$ crystal structure. The sample was then cooled to room temperature in air, mounted in epoxy resin and polished with standard metallography procedures to expose the cross-sectioned microstructure. A TEM lamellar of approximately $16 \mu \mathrm{m} \times 25 \mu \mathrm{m}$ was prepared using a focused ion beam (FIB) technique on a FEI Scios FIB-dual beam scanning electron microscope (SEM), similar to a technique described elsewhere [20]. The sample was extracted from a region of interest (ROI) at the $\mathrm{Cu} / \mathrm{IMCs} / \mathrm{SAC}$ interface (Figure 1a) and welded to a Cu TEM half grid by Pt deposition. Subsequently, the area of the lamellar containing the $\mathrm{Cu} / \mathrm{IMCs} / \mathrm{SAC}$ interfaces were thinned to $500 \mathrm{~nm}$.

The TEM lamellar was placed on the double-tilt heating TEM holder. From the TEM viewing screen, a $\mathrm{Cu}_{6} \mathrm{Sn}_{5}$ grain was selected. To enhance the image contrast in the thick (500 nm) sample, an in-column omega-type filter was used to filter the plasmon contributions to the image $[21,22]$. The sample was tilted to a low-index zone axis of this grain and selected area electron diffraction (SAED) patterns were obtained. The sample 
was then heated according to the temperature profile shown in Figure 1c. A high-resolution video recorder is used to capture the evolution of the selected $\mathrm{Cu}_{6} \mathrm{Sn}_{5}$ grain during the heating experiment at a frame rate of 1 frame per second. The sample was held at $190{ }^{\circ} \mathrm{C}$ for $30 \mathrm{~min}$, followed by $9 \mathrm{~min}$ at $150{ }^{\circ} \mathrm{C}$ and $25 \mathrm{~min}$ at $120^{\circ} \mathrm{C}$ before it was cooled to room temperature. Diffraction pattern of the on-zone grain was obtained at room temperature. All SAED patterns were analyzed with Gatan Digital Micrograph version 3.20.1314.0 (Gatan, Inc., Pleasanton, CA, USA) and SingleCrystal version 2.3.3 (CrystalMaker Software Ltd., Begbroke, UK), and the corresponding crystal structures were visualized with CrystalMaker version 9.2.8.
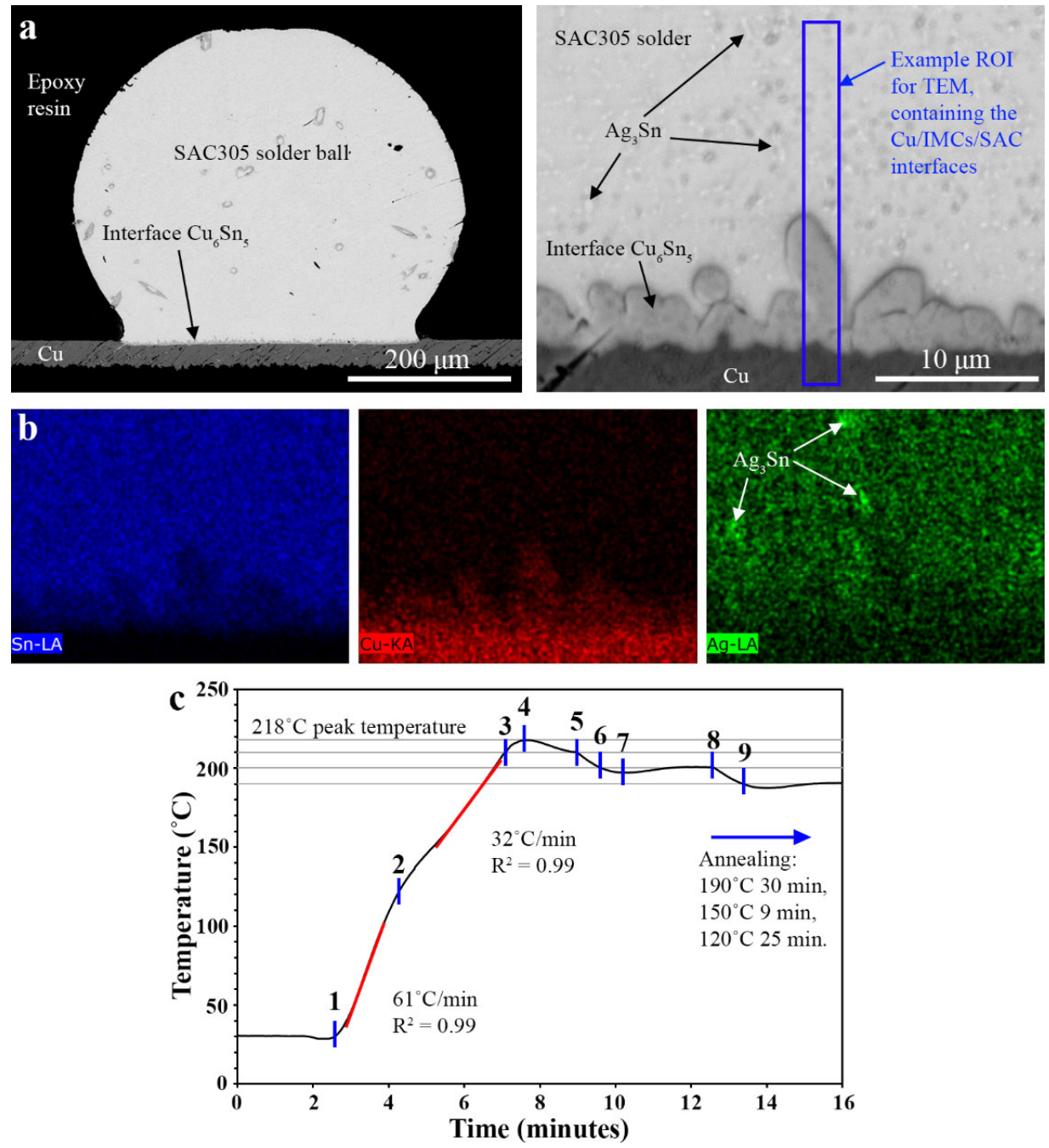

Figure 1. (a) SEM cross-section of the as reflowed $\mathrm{Cu} / \mathrm{IMCs} / \mathrm{SAC}$ solder joint at two different magnifications. (b) Sn, Cu and Ag EDS maps of the Cu/IMCs/SAC solder joint. (c) Temperature profile of the heating experiment, showing different time intervals (points 1-9) through the heating cycle.

\section{Results and Discussion}

The SEM cross-section of the SAC305 solder ball reflow soldered on to the OSP $\mathrm{Cu}$ pad is shown in Figure 1a along with a higher magnification image displaying the $\mathrm{Cu} / \mathrm{IMCs} / \mathrm{SAC}$ interface. The $\mathrm{Cu}_{6} \mathrm{Sn}_{5}$ IMC has a scalloped-like morphology. Under BSE mode, the Sn-rich SAC305 solder matrix has a good contrast with the $\mathrm{Cu}_{6} \mathrm{Sn}_{5} \mathrm{IMC}$ and the $\mathrm{Cu}$ substrate due to the differences in the averaged atomic numbers of approximately 50, 38.5 and 29, respectively. Ag has an atomic number of 47 which is relatively close to the atomic number of $\mathrm{Sn}$, therefore the contrast between $\mathrm{Ag}_{3} \mathrm{Sn}$ and the Sn-rich matrix is low. The brighter spots in the Ag-LA EDS map in Figure $1 \mathrm{~b}$ corresponds to the fine $\mathrm{Ag}_{3} \mathrm{Sn}$ plates, 
while the Sn-LA and Cu-KA maps help identify the Sn-rich SAC305 solder, the $\mathrm{Cu}_{6} \mathrm{Sn}_{5}$ IMC and the $\mathrm{Cu}$ substrate. The $\mathrm{Cu}_{3} \mathrm{Sn}$ IMC layer in the as reflowed joint was thin and was not visible due to the resolution limit of the SEM. The observed microstructure agrees with those widely reported in soldering literature $[23,24]$.

Figure $2 \mathrm{a}, \mathrm{b}$ show the TEM lamellar and an on-zone $\mathrm{Cu}_{6} \mathrm{Sn}_{5}$ grain, respectively. The $\mathrm{Cu}_{3} \mathrm{Sn}$ layer thickened as a result of ageing at $150{ }^{\circ} \mathrm{C}$ for $500 \mathrm{~h}[2,3,23]$. Kirkendall voids, which often accompany the formation of $\mathrm{Cu}_{3} \mathrm{Sn}[3]$, are present between the $\mathrm{Cu}_{3} \mathrm{Sn}$ and the OSP-Cu (Figure 2a). The selected grain is not directly connected to the OSP-Cu/ $\mathrm{Cu}_{3} \mathrm{Sn}$, and the boundaries between the on-zone grain and four other $\mathrm{Cu}_{6} \mathrm{Sn}_{5}$ grains are outlined in Figure 2b. The selected area electron diffraction (SAED) pattern of this grain in Figure $2 c$ is indexed to the [100] zone axis of $\eta^{\prime}-\mathrm{Cu}_{6} \mathrm{Sn}_{5}$ (monoclinic, C2/c, International Centre for Diffraction Data, ICDD number: 047-1575) crystal structure, at the crystal orientation shown in Figure $2 \mathrm{~d}$. The $\mathrm{Cu}_{6} \mathrm{Sn}_{5}$ grain grew with the c-axis of the equivalent $\eta-\mathrm{Cu}_{6} \mathrm{Sn}_{5}$ crystal structure (hexagonal, $\mathrm{P}_{3} / \mathrm{mmc}$, International Centre for Diffraction Data, ICDD number: 045-1488) perpendicular to the surface of the OSP-Cu, which is consistent with the preferred orientation reported in the literature [11].
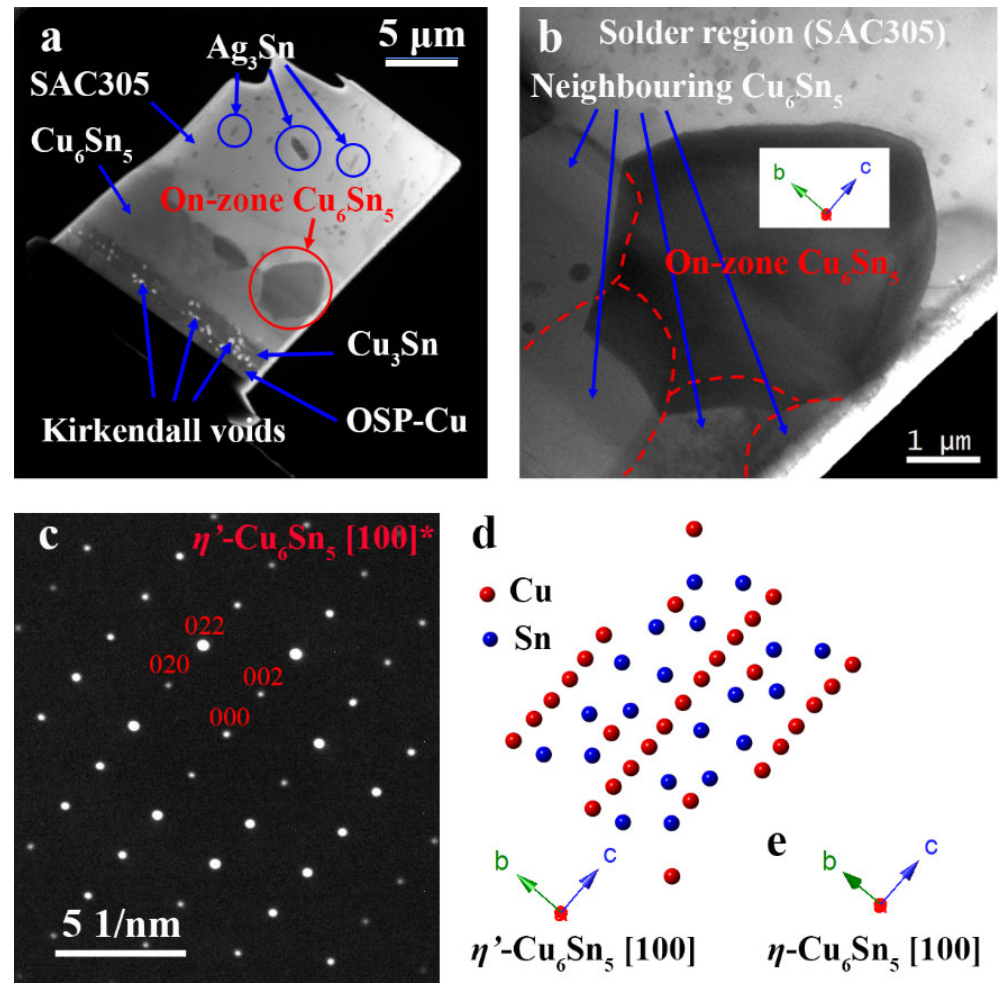

Figure 2. (a) Low magnification on-zone bright-field (BF) plasmon filtered TEM image of the lamellar before the heating experiment. (b) Image of the on-zone $\mathrm{Cu}_{6} \mathrm{Sn}_{5}$ on top of four other $\mathrm{Cu}_{6} \mathrm{Sn}_{5}$ grains, and (c) the SAED pattern of the on-zone grain (d) a schematic of the crystal structure showing the crystal orientation, and (e) the equivalent orientation in $\eta-\mathrm{Cu}_{6} \mathrm{Sn}_{5}$ crystal to produce the diffraction pattern indexed in (c).

Video S1 (Supplementary Materials) shows the recorded video during the heating experiment that is accelerated 20 times. Between point 1 and 2, the sample was heated to $120^{\circ} \mathrm{C}$ at a rate of $61^{\circ} \mathrm{C} / \mathrm{min}$. Between point 2 and 3 , the heating rate was reduced to $32{ }^{\circ} \mathrm{C} / \mathrm{min}$ to reduce temperature overshoot. It is expected that the $\mathrm{Cu}_{6} \mathrm{Sn}_{5}$ grains transform from a monoclinic $\eta^{\prime}$ crystal structure to a $\eta$ crystal structure around $186{ }^{\circ} \mathrm{C}$ [25] during this stage as observed in published TEM works $[4,6]$. During these heating stages, the selected $\mathrm{Cu}_{6} \mathrm{Sn}_{5}$ grain grew gradually (Figure $3 \mathrm{a}-\mathrm{c}$ ) until the temperature reached $211^{\circ} \mathrm{C}$ at point 3, where rapid changes in the morphology of the solid $\mathrm{Cu}_{6} \mathrm{Sn}_{5}$ were observed 
(Figure $3 c-i)$. Figure $3 c-g$ are 1-s interval snapshots over a 4 s period highlighting the rapid grain boundary movements starting from point 3 . It is believed that this point the SAC305 solder (solidus at $217{ }^{\circ} \mathrm{C}$ ) has started to melt while the $\mathrm{Cu}_{6} \mathrm{Sn}_{5}$ grain remained solid (solidus at $408^{\circ} \mathrm{C}$ ). The presence of liquid solder at this temperature is expected to enhance diffusion rates within the solder. The solidus is lower than the expected $217^{\circ} \mathrm{C}$, potentially due to electron beam heating. Since the metallic sample and the sample stage have good thermal conductivities, it is expected that the difference between the real sample temperature and the read-out temperature is small, though this may have also contributed to the sample melting at a lower read-out temperature. The sample appears to be selfsustaining despite the presence of liquid likely due to the mechanical strength imparted by the surface tension of the thin oxide film $\left(581 \mathrm{mN} \mathrm{m}^{-1}\right.$ at the melting point of Sn [26]), similar to the case in the Al-Si experiment conducted by Howe and Saka [12]. Furthermore, $\mathrm{Sn}$ has a vapor pressure at the order of $1 \times 10^{-20} \mathrm{~Pa}$ close to its melting point [27], that is orders of magnitude lower than the vapor pressure of $\mathrm{Al}$ alloys at the order of $7 \times 10^{-9} \mathrm{~Pa}$ at the Al-Si eutectic of $577^{\circ} \mathrm{C}$ [28] and is less likely to vaporize under the TEM vacuum. The dark contrast of the selected $\mathrm{Cu}_{6} \mathrm{Sn}_{5}$ grain is evidence that the grain remained solid throughout the heating experiment, as it continues to diffract the electron beam. The fast movement at the $\mathrm{Cu}_{6} \mathrm{Sn}_{5} / \mathrm{SAC}$ interface, measured up to $2.5 \mu \mathrm{m} / \mathrm{s}$ (movement of point $\mathrm{P}$ to point $\mathrm{Q}$ in Figure $3 \mathrm{~h}, \mathrm{i}$ ), is due to the dissolution of the solid $\mathrm{Cu}_{6} \mathrm{Sn}_{5}$, as observed during a second reflow in an ex-situ experiment performed by Gong et al. [11]. On the other hand, at the bottom left of the grain, which is closer to the $\mathrm{Cu}_{3} \mathrm{Sn}$ layer, grain growth towards the direction of the $\mathrm{Cu}$ source was observed.

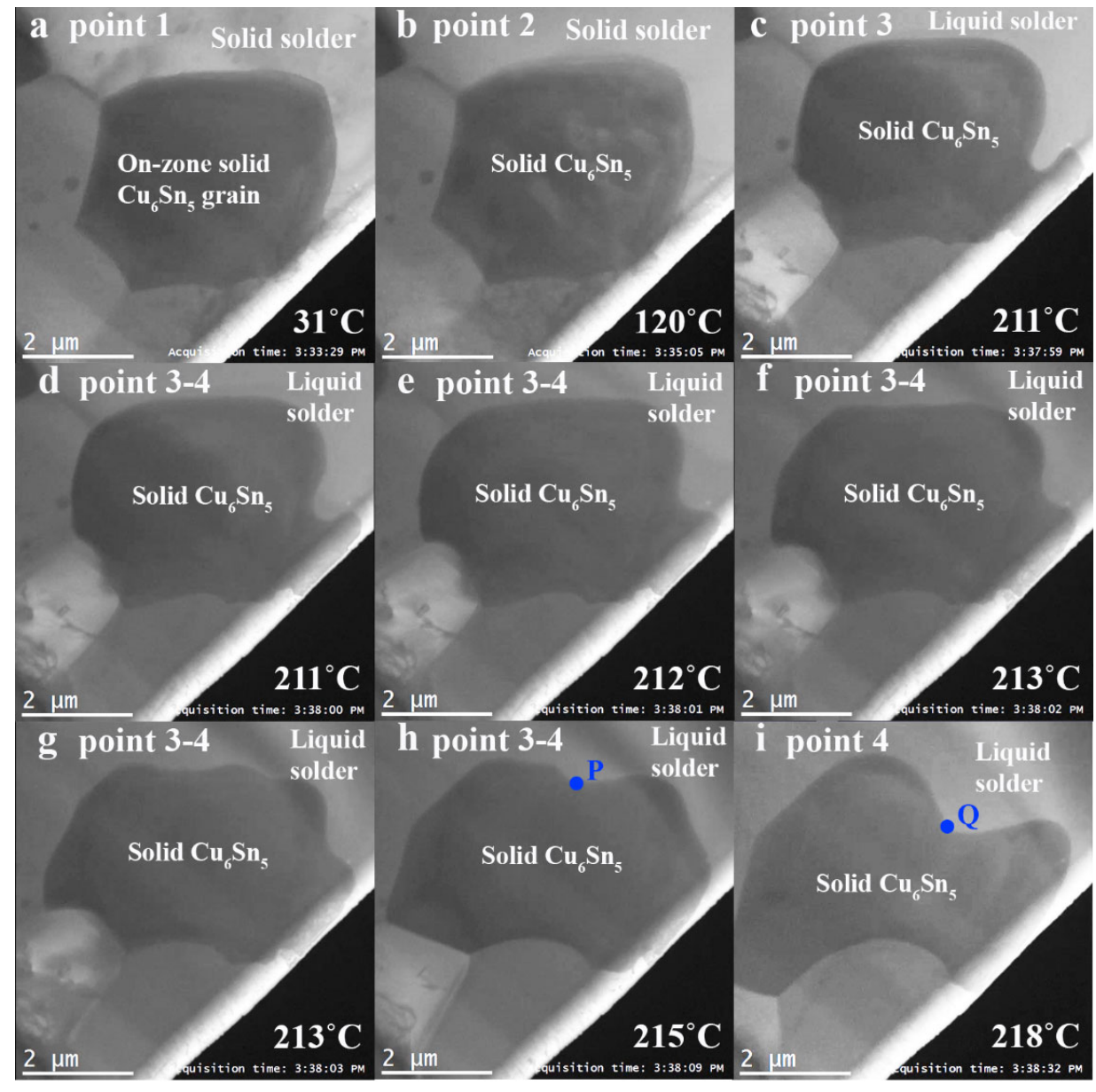

Figure 3. Snapshots of the heating experiment at each of the time intervals indicated in Figure 1c: (a) point 1, (b) point 2, (c-g) 1-s interval snapshots over a $4 \mathrm{~s}$ period highlighting the rapid grain boundary movements starting from point 3 , (h) between point 3 and 4 at $215^{\circ} \mathrm{C}$ and (i) point 4 . 
Sample heating was stopped shortly after point 3 after the rapid morphological changes were observed. The temperature overshot to $218^{\circ} \mathrm{C}$ at point 4 , before cooling to a set temperature of $210^{\circ} \mathrm{C}$ at point 5 and then $200{ }^{\circ} \mathrm{C}$ at point 6 , and was maintained at this near-isothermal temperature for $180 \mathrm{~s}$. The rapid grain boundary movements continued through from point 3 to point 7 (Figures $3 c-i$ and $4 a-c$ ). A second $\mathrm{Cu}_{6} \mathrm{Sn}_{5}$ grain nucleated at point 7 (Figure $4 \mathrm{~d}$ ), where a minimum temperature at $197^{\circ} \mathrm{C}$ was measured. In Figure $4 \mathrm{~d}$, the video is zoomed out to a lower magnification to provide a view of the area surrounding the selected $\mathrm{Cu}_{6} \mathrm{Sn}_{5}$ grain, where the grain boundaries of two adjacent grains are visible to the top-left of the selected grain. The morphological changes became sluggish from this point onwards (Figure 4d,e), as the SAC305 solder solidified. At this stage, the bottom left of the $\mathrm{Cu}_{6} \mathrm{Sn}_{5}$ grain has grown to less than $1 \mu \mathrm{m}$ from the $\mathrm{Cu}_{3} \mathrm{Sn}$. From point 8 to 9 , the sample was cooled to $190^{\circ} \mathrm{C}$. During cooling, the growth rate of the two $\mathrm{Cu}_{6} \mathrm{Sn}_{5}$ grains accelerated (Figure 4e,f), as the dissolution limit of $\mathrm{Cu}$ in the SAC alloy reduced with temperature [11], and the excess $\mathrm{Cu}$ was deposited onto the $\mathrm{Cu}_{6} \mathrm{Sn}_{5}$ grains. Gong et al. [11] state that the heterogeneous dissolution and growth may have resulted in the scallop morphology of the $\mathrm{Cu}_{6} \mathrm{Sn}_{5}$ phase. The in situ observation in this study shows the $\mathrm{Cu}_{6} \mathrm{Sn}_{5}$ grain does not have a scallop morphology during dissolution, and the scallop morphology is formed when $\mathrm{Cu}$ is deposited onto the $\mathrm{Cu}_{6} \mathrm{Sn}_{5}$ grains during cooling.

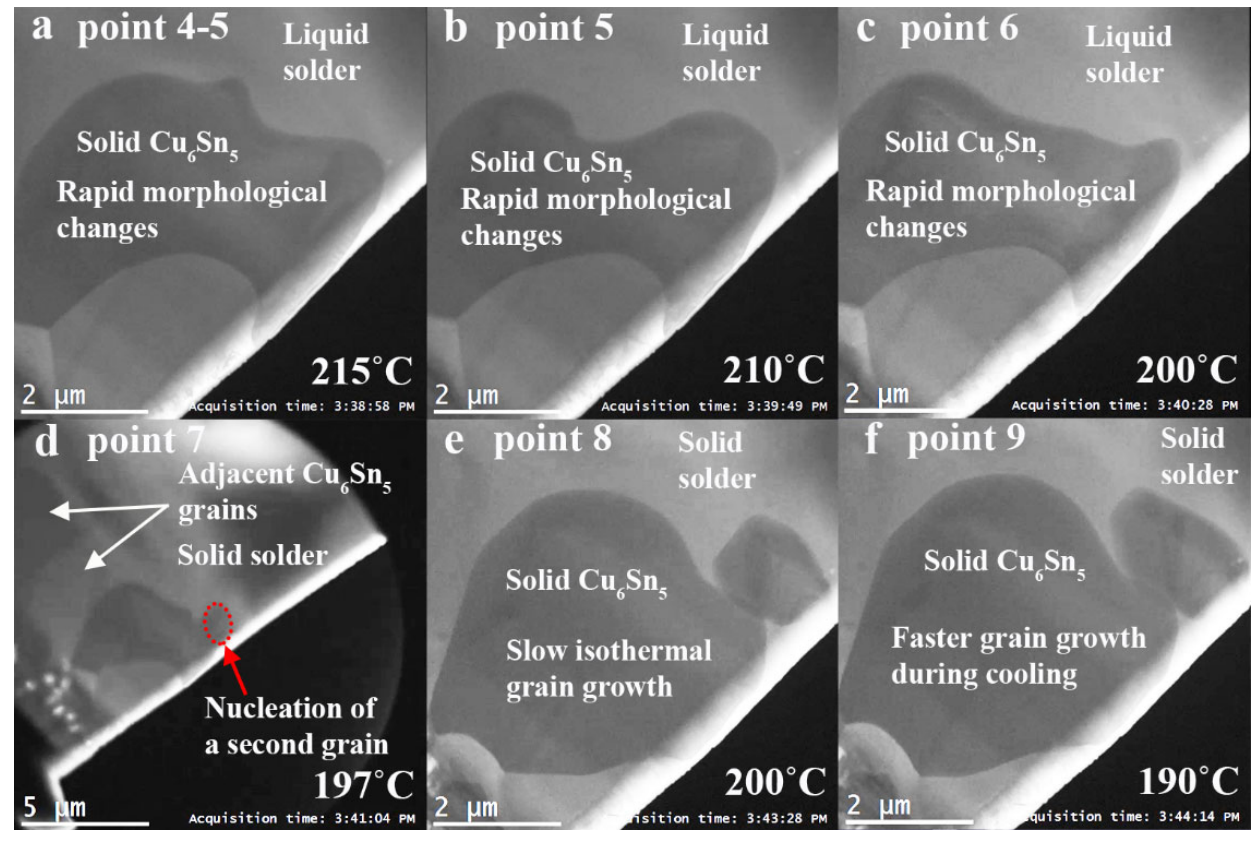

Figure 4. Snapshots of the heating experiment (a) between point 4 and 5, (b) at point 5, (c) point 6, (d) point 7 (zoomed out to provide a view of the area surrounding the selected grain), (e) point 8 and (f) point 9 .

The Gibbs-Thomson effect results in chemical potential variations across the curved interface between the solid $\mathrm{Cu}_{6} \mathrm{Sn}_{5}$ and liquid solder which can lead to undercooling $[29,30]$. The concentration of $\mathrm{Cu}$ in liquid solder at the localized surface of the grain, $C_{r}$, is given by [31]

$$
C_{r} \cong C_{0}\left(1+\frac{2 \gamma_{S L} \Omega}{r R T}\right) \text {, when } \frac{2 \gamma_{S L} \Omega}{r R T} \ll 1,
$$

where $C_{0}$ is the concentration of $\mathrm{Cu}$ in the solder, $\gamma_{S L}$ is the solid-liquid interfacial energy, $\Omega$ is the molar volume of $\mathrm{Cu}_{6} \mathrm{Sn}_{5}, R$ is the gas constant, $T$ is the temperature, and $r$ is the radius of curvature which is positive for a convex grain interface and negative for a concave grain interface [32]. Therefore, a convex $\mathrm{Cu}_{6} \mathrm{Sn}_{5}$ interface of small curvature radius $r$, will increase the local concentration of $\mathrm{Cu}$ while a concave surface will result in a local $\mathrm{Cu}$ concentration that is lower than the $\mathrm{Cu}$ concentration in the solder. As a result, apart from 
the $\mathrm{Cu}$ fluxes from $\mathrm{Cu}_{3} \mathrm{Sn}$ and the adjacent $\mathrm{Cu}_{6} \mathrm{Sn}_{5}$ grains which promotes grain growth and Ostwald ripening [31,33], there is also $\mathrm{Cu}$ flux exchange at different local interfaces within a grain due to the difference in curvature radii, which may have contributed to the rapid changes in morphology at the $\mathrm{Cu}_{6} \mathrm{Sn}_{5} /$ liquid interface. The $\mathrm{Cu}$ flux, J, can be calculated by the following equation [31],

$$
J=-D \frac{C_{r 1}-C_{r 2}}{L}=-\frac{2 \gamma_{S L} \Omega D C_{0}}{L R T}\left(\frac{1}{r_{1}}-\frac{1}{r_{2}}\right),
$$

where $D$ is the diffusivity of $\mathrm{Cu}$ in liquid solder, $C_{r 1}$ and $C_{r 2}$ are the $\mathrm{Cu}$ concentrations in liquid solder at two localized point surfaces calculated by Equation (1), $L$ is the distance between the two points, and $r_{1}$ and $r_{2}$ are the radii of curvature at point 1 and point 2 respectively.

After the real-time observation, the sample was held at $190{ }^{\circ} \mathrm{C}$ for $30 \mathrm{~min}$. Again, slow grain growth was observed during this period. This was followed by $9 \mathrm{~min}$ at $150{ }^{\circ} \mathrm{C}$ and $25 \mathrm{~min}$ at $120^{\circ} \mathrm{C}$ before the sample was cooled to room temperature (Figure 5a,b). The sample was again tilted to a low index zone axis of the selected $\mathrm{Cu}_{6} \mathrm{Sn}_{5}$ grain and the SAED pattern was captured and indexed (Figure $5 c$ ). As indicated by the monoclinic reflections in Figure $5 c$, the grain has the crystal structure of a $\eta^{\prime}-\mathrm{Cu}_{6} \mathrm{Sn}_{5}$, which is expected as the annealing stages allowed the high temperature $\eta$ to fully convert into $\eta^{\prime}$ as observed by Somidin et al. under HV-TEM [4,5]. The grain orientation is unchanged (Figure 5b,c), with the c-axis of an equivalent $\eta-\mathrm{Cu}_{6} \mathrm{Sn}_{5}$ crystal perpendicular to the OSP-Cu (Figure 5c,e). The low resolution plasmon filtered image of the sample in Figure 5a shows significant growth in all $\mathrm{Cu}_{6} \mathrm{Sn}_{5}$ grains in the direction perpendicular to the OSP-Cu. In contrast, no $\mathrm{Cu}_{6} \mathrm{Sn}_{5}$ grain coalescence was observed and there is no lateral growth.
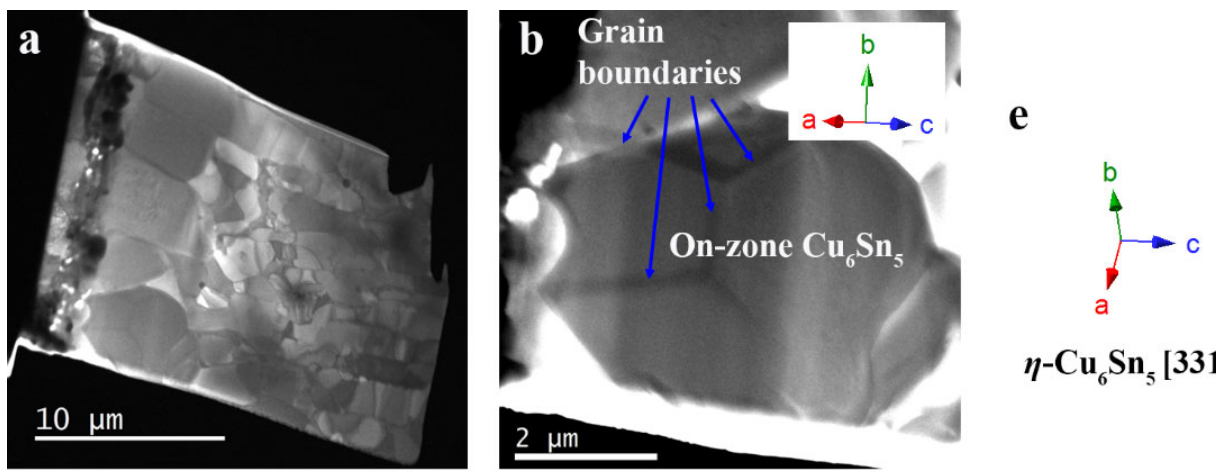

$\eta-\mathrm{Cu}_{6} \mathrm{Sn}_{5}[331]$
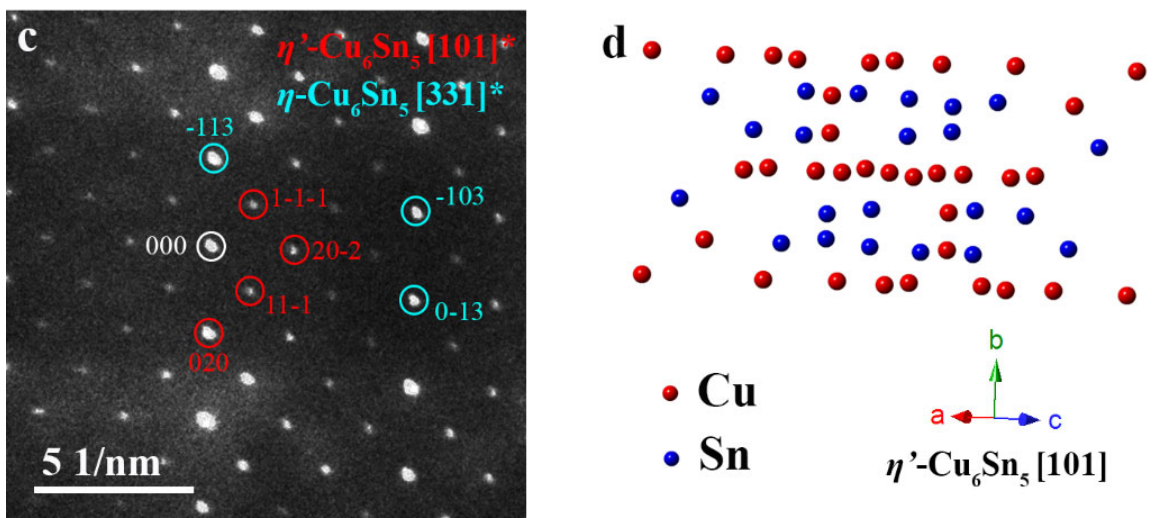

Figure 5. (a) Low magnification image of the lamellar after the heating experiment, (b) image of the on-zone $\mathrm{Cu}_{6} \mathrm{Sn}_{5}$ grain after tilting, (c) the SAED pattern and (d) a schematic of the crystal structure of the on-zone $\eta^{\prime}-\mathrm{Cu}_{6} \mathrm{Sn}_{5}$ grain showing the grain orientation, and (e) the equivalent orientation in a $\eta-\mathrm{Cu}_{6} \mathrm{Sn}_{5}$ crystal to produce the diffraction pattern indexed in (c). 
After 30 min of annealing at $190^{\circ} \mathrm{C}$, part of the selected $\mathrm{Cu}_{6} \mathrm{Sn}_{5}$ grain has connected to the $\mathrm{Cu}_{3} \mathrm{Sn}$ phase. The growth in this direction continued during subsequent annealing at $150{ }^{\circ} \mathrm{C}$ and $120{ }^{\circ} \mathrm{C}$, resulting in the final microstructure shown in Figure 5a,b. Again, the Ostwald ripening growth model $[31,33]$ was not observed and there is no lateral growth during the annealing stages. Lord et al. [9] reported that lateral growth begins after the concentration of $\mathrm{Cu}$ in the solder reaches the dissolution limit. It is likely that the SAC305 in this experiment was not saturated due to the relatively short time above the melting temperature of the solder, which explains the lack of lateral growth.

\section{Conclusions}

The presented results are the first direct in situ observation of the dissolution of $\mathrm{Cu}_{6} \mathrm{Sn}_{5}$ at the solid $\mathrm{Cu}_{6} \mathrm{Sn}_{5} /$ liquid solder interface and $\mathrm{Cu}_{6} \mathrm{Sn}_{5}$ growth at the $\mathrm{Cu}_{6} \mathrm{Sn}_{5} / \mathrm{Cu}_{3} \mathrm{Sn}$ interface at these temperatures. With this, the singular behavior of the solid/liquid interface with a weak surface tension is disclosed. That is, the phase boundary between $\mathrm{Cu}_{6} \mathrm{Sn}_{5}$ and SAC305 softened significantly when the latter is in a molten state, likely owing to repeated partial dissolution and re-solidification of $\mathrm{Cu}_{6} \mathrm{Sn}_{5}$ into and from SAC305.

The observation is consistent with published snapshots of the process based on ex-situ techniques in Gong et al.'s work, using a Sn-Ag-Cu alloy with slightly higher alloying contents i.e., Sn-3.8 wt\%Ag-0.7 wt\%Cu [11]. As long as the composition of the solder is below the solubility limits, $\mathrm{Cu}_{6} \mathrm{Sn}_{5}$ dissolves into the solder resulting in rapid changes in grain morphology above the solidus of the solder. Furthermore, the growth of $\mathrm{Cu}_{6} \mathrm{Sn}_{5}$ in the direction of $\mathrm{Cu}_{3} \mathrm{Sn}$ ( $\mathrm{Cu}$ source) is substantial during soldering at high temperature; while the growth in the direction of the solder happens during cooling due to the deposition of $\mathrm{Cu}$ from the melt as the solubility of $\mathrm{Cu}$ reduces with decreasing temperature. This observation can help in designing strategies to reduce the thickness of the brittle $\mathrm{Cu}_{6} \mathrm{Sn}_{5}$ IMCs which are a primary failure point in solder joints and improve joint reliability, for example, by applying a temperature gradient to drive the diffusion of $\mathrm{Cu}$ away from the IMC/liquid interface and by replenishing the solder bath during wave soldering with solder alloys of lower $\mathrm{Cu}$ to maintain the $\mathrm{Cu}$ concentration in the melt.

This method for observing solid/liquid interaction using HV-TEM is likely to find application for other alloy/substrate systems such as those found in coating or welding processes to provide further understandings of the mechanisms involved. While the HV-TEM method allows for the use of thicker samples and edge-effects are less likely to influence the observed microstructural changes, further work is required to determine how closely these processes approach those occurring in bulk samples of industrially significant length scales.

Supplementary Materials: The following are available online at https:/ /www.mdpi.com/article/10

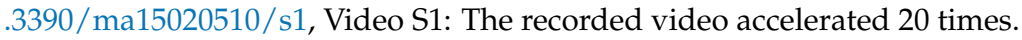

Author Contributions: Conceptualization, K.N. and S.M.; methodology, F.S., K.N. and H.M.; validation, X.F.T., S.D.M. and M.J.B.; formal analysis, X.F.T., F.S. and K.N.; investigation, F.S., K.N. and H.M.; resources, K.N. and S.M.; writing—original draft preparation, X.F.T.; writing-review and editing, X.F.T., F.S., M.J.B., S.D.M., S.M. and K.N.; visualization, X.F.T. and F.S.; supervision, K.N.; project administration, K.N.; funding acquisition, K.N. and S.M. All authors have read and agreed to the published version of the manuscript.

Funding: This work was supported by the University of Queensland (UQ) [UQ-KU project], Nihon Superior [2016001895], the Australian Research Council [DP200101949], MEXT Japan [JPMXP09-A-17KU-224], and Kyushu University [Progress 100 program].

Institutional Review Board Statement: Not applicable.

Informed Consent Statement: Not applicable.

Data Availability Statement: The data presented in this study are available on request from the corresponding author. 
Acknowledgments: The authors acknowledge the facilities, and the scientific and technical assistance, of the Australian Microscopy \& Microanalysis Research Facility at the Centre for Microscopy and Microanalysis, The University of Queensland, in particular for the access to the FIB SCIOS system for TEM sample preparation.

Conflicts of Interest: The authors declare no conflict of interest.

\section{References}

1. Cheng, S.; Huang, C.-M.; Pecht, M. A review of lead-free solders for electronics applications. Microelectron. Reliab. 2017, 75, 77-95. [CrossRef]

2. Mayappan, R.; Ghani, N.A.A.; Yahya, I. The effect of Ni addition on Cu-Sn intermetallic growth rate values in the SAC solder. AIP Conf. Proc. 2018, 2031, 020016. [CrossRef]

3. Ng, W.C.W.; Sweatman, K.; Akaiwa, T.; Nishimura, T.; Sato, M.; Gourlay, C.; Belyakov, S. Dissolution in service of the copper substrate of solder joints. In Proceedings of the 2016 IEEE 18th Electronics Packaging Technology Conference (EPTC), Singapore, 30 November-3 December 2016.

4. Somidin, F.; Maeno, H.; Mohd Salleh, M.A.A.; Tran, X.Q.; McDonald, S.D.; Matsumura, S.; Nogita, K. Characterising the polymorphic phase transformation at a localised point on a $\mathrm{Cu}_{6} \mathrm{Sn}_{5}$ grain. Mater. Charact. 2018, 138, 113-119. [CrossRef]

5. Somidin, F.; Maeno, H.; Tran, X.Q.; McDonald, S.D.; Mohd Salleh, M.A.A.; Matsumura, S.; Nogita, K. Imaging the Polymorphic Transformation in a Single $\mathrm{Cu}_{6} \mathrm{Sn}_{5}$ Grain in a Solder Joint. Materials 2018, 11, 2229. [CrossRef] [PubMed]

6. Somidin, F.; Maeno, H.; Toriyama, T.; McDonald, S.D.; Yang, W.; Matsumura, S.; Nogita, K. Direct observation of the Ni stabilising effect in interfacial $(\mathrm{Cu}, \mathrm{Ni})_{6} \mathrm{Sn}_{5}$ intermetallic compounds. Materialia 2020, 9, 100530. [CrossRef]

7. Mohd Salleh, M.A.A.; McDonald, S.D.; Yasuda, H.; Sugiyama, A.; Nogita, K. Rapid $\mathrm{Cu}_{6} \mathrm{Sn}_{5}$ growth at liquid Sn/solid Cu interfaces. Scr. Mater. 2015, 100, 17-20. [CrossRef]

8. Mohd Salleh, M.A.A.; Gourlay, C.M.; Xian, J.W.; Belyakov, S.A.; Yasuda, H.; McDonald, S.D.; Nogita, K. In situ imaging of microstructure formation in electronic interconnections. Sci. Rep. 2017, 7, 40010. [CrossRef]

9. Lord, R.A.; Umantsev, A. Early stages of soldering reactions. J. Appl. Phys. 2005, 98, 063525. [CrossRef]

10. Pan, C.-C.; Yu, C.-H.; Lin, K.-L. The amorphous origin and the nucleation of intermetallic compounds formed at the interface during the soldering of Sn-3.0Ag-0.5Cu on a Cu substrate. Appl. Phys. Lett. 2008, 93, 061912. [CrossRef]

11. Gong, J.; Liu, C.; Conway, P.P.; Silberschmidt, V.V. Evolution of CuSn intermetallics between molten $\mathrm{SnAgCu}$ solder and Cu substrate. Acta Mater. 2008, 56, 4291-4297. [CrossRef]

12. Howe, J.M.; Saka, H. In Situ Transmission Electron Microscopy Studies of the Solid-Liquid Interface. MRS Bull. 2011, 29, 951-957. [CrossRef]

13. Matsuki, H.; Ibuka, H.; Saka, H. TEM observation of interfaces in a solder joint in a semiconductor device. Sci. Technol. Adv. Mater. 2002, 3, 261-270. [CrossRef]

14. Saka, H.; Sasaki, K.; Tsukimoto, S.; Arai, S. In situ Observation of Solid-liquid Interfaces by Transmission Electron Microscopy. J. Mater. Res. 2005, 20, 1629-1640. [CrossRef]

15. Torazawa, N.; Arai, S.; Takase, Y.; Sasaki, K.; Saka, H. Transmission Electron Microscopy of Interfaces in Joints between Pb-Free Solders and Electroless Ni-P. Mater. Trans. 2003, 44, 1438-1447. [CrossRef]

16. Lee, J.G.; Mori, H. In-situobservation of alloy phase formation in nanometre-sized particles in the Sn-Bi system. Philos. Mag. 2004, 84, 2675-2686. [CrossRef]

17. Lee, J.G.; Mori, H.; Yasuda, H. In situobservation of a fluid amorphous phase formed in isolated nanometer-sized particles in the Sn-Bi system. Phys. Rev. B 2002, 66, 012105. [CrossRef]

18. Allen, G.L.; Bayles, R.A.; Gile, W.W.; Jesser, W.A. Small particle melting of pure metals. Thin Solid Film. 1986, 144, 297-308. [CrossRef]

19. Lai, S.L.; Guo, J.Y.; Petrova, V.V.; Ramanath, G.; Allen, L.H. Size-Dependent Melting Properties of Small Tin Particles: Nanocalorimetric Measurements. Phys. Rev. Lett. 1996, 77, 99-102. [CrossRef] [PubMed]

20. Tan, X.F.; Yang, W.; Aso, K.; Matsumura, S.; McDonald, S.D.; Nogita, K. Evidence of Copper Separation in Lithiated Cu $\mathrm{Sn}_{5}$ Lithium-Ion Battery Anodes. ACS Appl. Energy Mater. 2019, 3, 141-145. [CrossRef]

21. Sadamatsu, S.; Tanaka, M.; Higashida, K.; Matsumura, S. Transmission electron microscopy of bulk specimens over 10microm in thickness. Ultramicroscopy 2016, 162, 10-16. [CrossRef] [PubMed]

22. Omoto, K.; Tsuno, K.; Ohsaki, M.; Matsumura, S.; Tomokiyo, Y. Omega filter installed in the $1 \mathrm{MV}$ microscope of Kyushu University. Micron 2008, 39, 666-675. [CrossRef]

23. Zhang, X.; Hu, X.; Jiang, X.; Li, Y. Effect of Ni addition to the $\mathrm{Cu}$ substrate on the interfacial reaction and IMC growth with Sn3.0Ag0.5Cu solder. Appl. Phys. A 2018, 124, 315. [CrossRef]

24. Li, S.; Liu, Y.; Zhang, H.; Cai, H.; Sun, F.; Zhang, G. Microstructure and hardness of SAC305 and SAC305-0.3Ni solder on Cu, high temperature treated $\mathrm{Cu}$, and graphene-coated $\mathrm{Cu}$ substrates. Results Phys. 2018, 11, 617-622. [CrossRef]

25. Zeng, G.; McDonald, S.D.; Read, J.J.; Gu, Q.; Nogita, K. Kinetics of the polymorphic phase transformation of Cu ${ }_{6} \mathrm{Sn}_{5}$. Acta Mater. 2014, 69, 135-148. [CrossRef] 
26. Passerone, A.; Ricci, E.; Sangiorgi, R. Influence of oxygen contamination on the surface tension of liquid tin. J. Mater. Sci. 1990, 25, 4266-4272. [CrossRef]

27. Lide, D.R. CRC Handbook of Chemistry and Physics, 87th ed Editor-in-Chief: David R. Lide (National Institute of Standards and Technology). CRC Press/Taylor and Francis Group: Boca Raton, FL. 2006. 2608 pp. \$139.95. ISBN 0-8493-0487-3. J. Am. Chem. Soc. 2006, 129, 724. [CrossRef]

28. Jeong, J.; Lee, S.; Jeon, J.-B.; Kim, S. Excessively High Vapor Pressure of Al-based Amorphous Alloys. Metals 2015, 5, 1878-1886. [CrossRef]

29. Xian, J.W.; Belyakov, S.A.; Ivier, M.; Nogita, K.; Yasuda, H.; Gourlay, C.M. $\mathrm{Cu}_{6} \mathrm{Sn}_{5}$ crystal growth mechanisms during solidification of electronic interconnections. Acta Mater. 2017, 126, 540-551. [CrossRef]

30. Nakano, K.; Narumi, T.; Morishita, K.; Yasuda, H. Characterization of Growing Dendrites in CrMnFeCoNi High-Entropy Alloy by Time-Resolved and In-Situ Tomography. Mater. Trans. 2020, 61, 596-604. [CrossRef]

31. Kim, H.K.; Tu, K.N. Kinetic analysis of the soldering reaction between eutectic $\mathrm{SnPb}$ alloy and Cu accompanied by ripening. Phys. Rev. B Condens. Matter. 1996, 53, 16027-16034. [CrossRef]

32. Gusak, A.M.; Tu, K.N.; Chen, C. Extremely rapid grain growth in scallop-type $\mathrm{Cu}_{6} \mathrm{Sn}_{5}$ during solid-liquid interdiffusion reactions in micro-bump solder joints. Scr. Mater. 2020, 179, 45-48. [CrossRef]

33. Kim, H.K.; Liou, H.K.; Tu, K.N. Three-dimensional morphology of a very rough interface formed in the soldering reaction between eutectic SnPb and Cu. Appl. Phys. Lett. 1995, 66, 2337-2339. [CrossRef] 